\title{
Serum myoglobin level as diagnostic test in patients with acute myocardial infarction ${ }^{1}$
}

\author{
M. J. STONE, M. R. WATERMAN, D. HARIMOTO, G. MURRAY, \\ NANCY WILLSON, M. R. PLATT, G. BLOMQVIST, AND J. T. WILLERSON
}

From the Departments of Internal Medicine (Evelyn L. Overton Hematology-Oncology Laboratory and Cardiac Unit), Biochemistry and Surgery at the University of Texas Health Science Center at Dallas, Dallas, Texas, U.S.A.

Serum myoglobin levels were measured in normal subjects and patients by means of a newly developed radioimmunoassay. Myoglobin was identified in all of 135 sera from normal adults and ranged between 6 and $85 \mathrm{ng} / \mathrm{ml}$ (mean $\pm S E 31 \pm 1 \cdot 3$ ). Raised myoglobin levels were present in 62 of 64 patients with documented acute myocardial infarction, the mean serum concentration being $528 \pm 76 \mathrm{ng} / \mathrm{ml}$. Serial determinations in 46 patients with acute infarct showed that maximum values usually occurred within 4 hours after admission. In 19 of 42 cases, raised myoglobin levels preceded the rise in creatine kinase (CK) values; in the remaining patients, both serum myoglobin and creatine kinase were increased on admission. Only 2 of an additional 44 patients admitted with chest pain but without subsequent electrocardiographic, enzyme, or technetium-99m stannous pyrophosphate myocardial scintigraphic evidence of acute myocardial infarction had raised myoglobin levels; the mean value for this group was within the normal range $(44 \pm 6 \mathrm{ng} / \mathrm{ml})$. Serum myoglobin values also were normal in patients with congestive heart failure without acute myocardial infarction, and in patients after moderate exercise and cardiac catheterisation. Transient myoglobinaemia appears to be one of the earliest laboratory abnormalities occurring in acute myocardial infarction and, therefore, should prove useful as a diagnostic aid in patients.

The diagnosis of acute myocardial infarction has been traditionally based on a characteristic clinical history and typical electrocardiographic and serum enzyme findings. However, these diagnostic tests are insufficient to establish the diagnosis in every instance. Therefore, efforts continue to be made to find additional means of documenting the presence and extent of myocardial necrosis (Wagner et al., 1973; Holman et al., 1974; Willerson et al., 1975a). Substantial evidence suggests that damage to the cardiac muscle mass might result in release of myoglobin as well as various intracellular enzymes into the circulation. Thus, other investigators have reported that myoglobin is transiently detectable in urine or serum of some patients with acute myocardial infarction (Saranchak and Bernstein, 1974; Kagen et al., 1975; Jutzy et al., 1975; Kessler et al., 1975). For these reasons, we have recently developed a competitive binding radioimmunoassay

${ }^{1}$ This study was supported in part by NIH Ischemic Heart Disease Specialized Center of Research (SCOR) Grant HL-17669, and by American Heart Association Grant 75-819. Dr. Willerson is an Established Investigator of the American Heart Association.

Received for publication 18 October 1976 for myoglobin which is more sensitive than previously described methods (Stone et al., 1975).

The purpose of this report is to describe the incidence, magnitude, and time course of myoglobinaemia in patients with acute myocardial infarction and to compare results in this group with those obtained in patients admitted to the hospital for chest pain but without evidence of acute infarction. In addition, we have measured serum myoglobin levels in individuals after exercise testing, cardiac catheterisation, open heart surgery, and skeletal muscle damage.

\section{Methods}

\section{RADIOIMMUNOASSAY}

Serum myoglobin levels were determined by radioimmunoassay as previously described (Stone et al., 1975) except that we have recently determined that a 4-hour incubation period is adequate for sensitive and reliable determinations of serum myoglobin values using our radioimmunoassay. In brief, myoglobin isolated from human cardiac muscle ob- 
tained at necropsy was used to immunise rabbits. Antisera containing high affinity antibodies to myoglobin were employed in a radioimmunoassay procedure in which unlabelled myoglobin standards or unknown serum samples compete with ${ }^{125}$ I-myoglobin for specific antibody combining sites. Separation of free from antibody-bound labelled myoglobin was accomplished by means of ammonium sulphate precipitation and the results calculated by usual methods. Standard curves were run with each assay and all determinations performed in triplicate. Values obtained in triplicate agreed with one another within 5 per cent. This system is capable of detecting $0.5 \mathrm{ng}$ myoglobin and is not affected by haemolysis, lipaemia, or prolonged storage of serum at $-20^{\circ} \mathrm{C}$.

\section{INDIVIDUALS STUDIED}

Myoglobin levels were determined in sera from I: 135 normal adults (blood-bank donors) and II: pooled sera from 100 medical students.

The following patient groups were studied: (III) 64 patients admitted to the Coronary Care Unit (CCU) at Parkland Memorial Hospital, Dallas, Texas, for chest pain, who subsequently showed typical alterations by electrocardiogram, cardiac enzymes, and technetium-99m stannous pyrophosphate myocardial scintigraphy of acute myocardial infarction; (IV) 44 patients admitted to the CCU for chest pain but without subsequent evidence of acute myocardial infarction by the above criteria; (V) 17 patients with congestive heart failure but without recent myocardial infarction; (VI) 19 patients undergoing open heart surgery; (VII) 9 patients undergoing cardiac catheterisa- tion; (VIII) patients exercised on the bicycle ergometer as part of a standard exercise test to evaluate the possible presence of coronary artery disease; and (IX) 5 patients with rhabdomyolysis. All sera were stored at $-20^{\circ} \mathrm{C}$ before assay.

\section{Results}

NORMAL INDIVIDUALS (Groups I and II)

Myoglobin was identified by radioimmunoassay in all of 135 sera from normal adults and ranged between 6 and $85 \mathrm{ng} / \mathrm{ml}$ (mean \pm SE $31 \pm 1.3 \mathrm{ng} / \mathrm{ml}$ ) (Fig. 1). Pooled sera from 100 medical students yielded similar results (mean \pm SE $25 \pm 1.2 \mathrm{ng} / \mathrm{ml}$ in 10 separate assays) and were included in each experiment. The upper limit of normal was taken as $85 \mathrm{ng} / \mathrm{ml}$ which was the highest value observed in any normal individual; this value was greater than two standard deviations from the mean.

\section{ACUTE MYOCARDIAL INFARCTION (Group III)}

Of 64 patients with documented acute myocardial infarction, 62 had raised serum myoglobin values on admission (mean \pm SE $528 \pm 76 \mathrm{ng} / \mathrm{ml}$ ) (Fig. 1). The average age of these patients was 55 years and 54 were men. Thirty patients had anterior, 27 inferior, and 7 subendocardial myocardial infarction. Fortysix patients in this acute infarction group had serial serum myoglobin levels determined every 2 hours for 36 hours after admission. Of the 46 patients studied serially, 40 had peak myoglobin levels within 4 hours after admission and 24 of these had peak levels initially. The values returned to normal within 12 hours in 6 patients and were normal in 41 per cent $(19 / 46)$ of patients by 36 hours. In 42 of the 64

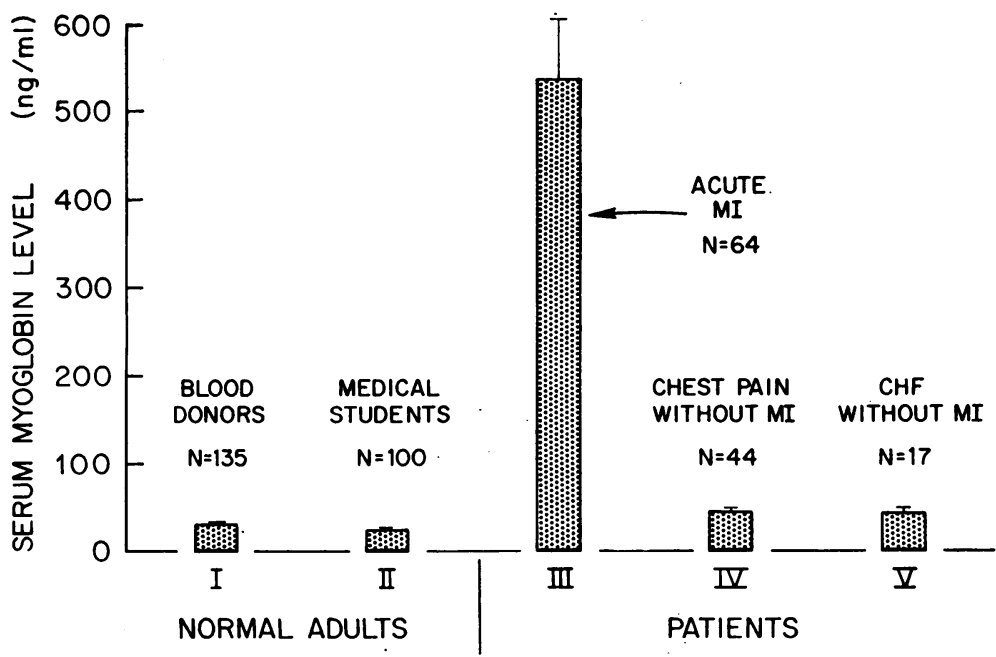

Fig. 1 Serum myoglobin levels in normal adults and patients. The upper limit of normal was $85 \mathrm{ng} / \mathrm{ml}$. Raised levels were found in 62 of 64 patients with acute myocardial infarction (Group III), 2 of 44 patients with chest pain but without acute infarction (group IV), and 1 of 17 patients with congestive heart failure but without acute infarction (group V). Brackets indicate standard error of the mean. 


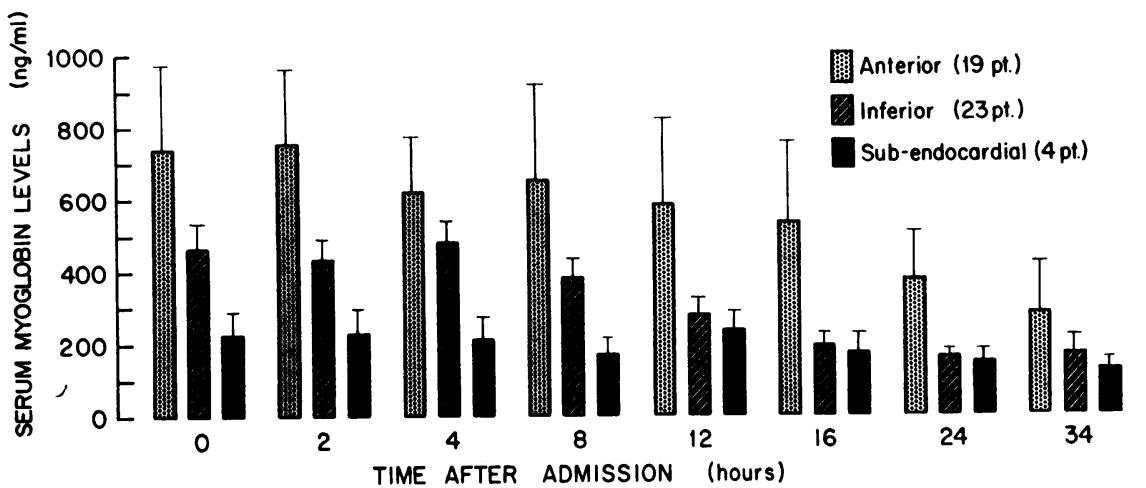

Fig. 2 Serum

myoglobin levels determined serially in 46 patients with acute myocardial infarction. Though mean values in patients with anterior infarcts were higher than those in patients with inferior or subendocardial infarctions, they were not statistically significant $(P>0.05)$.

patients, blood samples for total creatine kinase (CK) as well as myoglobin were obtained on admission; in 19 of these 42 the myoglobin level was raised while the CK value was within the normal range. The serum $C K$ values in these 19 patients subsequently did rise helping to establish the diagnosis of acute myocardial infarction. In the remaining patients, both myoglobin and CK were increased on admission.

No significant difference in serum myoglobin levels was observed between patients with acute anterior, inferior, or subendocardial infarction (Fig. 2). However, in those patients studied serially, serum myoglobin levels were statistically significantly higher (Mann-Whitney U-test) (Siegel, 1956) in patients who developed congestive heart failure after acute myocardial infarction (Fig. 3).

Two patients with acute infarction did not have raised serum myoglobin levels. Since our serial studies show that peak myoglobin levels occur early and fall toward normal in many patients, it is possible that the levels in these 2 patients had returned to normal by the time serum samples were available. Alternatively, these patients may have had quantitatively small infarcts which did not result in abnormally high levels of serum myoglobin.

CHEST PAIN WITHOUT ACUTE MYOCARDIAL INFARCTION (Group IV)

In 42 of 44 patients admitted to the CCU with chest pain but who did not show subsequent electrocardiographic, enzymatic, or scintigraphic evidence of acute infarction, serum myoglobin levels on admission remained within the normal range. Serial values on specimens obtained at 2-hour intervals for 36 hours from 5 of these patients also were normal. The 2 exceptions were a patient who had digitalis toxicity with electrocardiographic abnormalities suggestive of myocardial ischaemia $(140 \mathrm{ng} / \mathrm{ml}$ ) and a patient admitted with ventricular tachycardia $(224 \mathrm{ng} / \mathrm{ml})$. The mean value for this group was $44 \pm 6.0 \mathrm{ng} / \mathrm{ml}$ (Fig. 1).

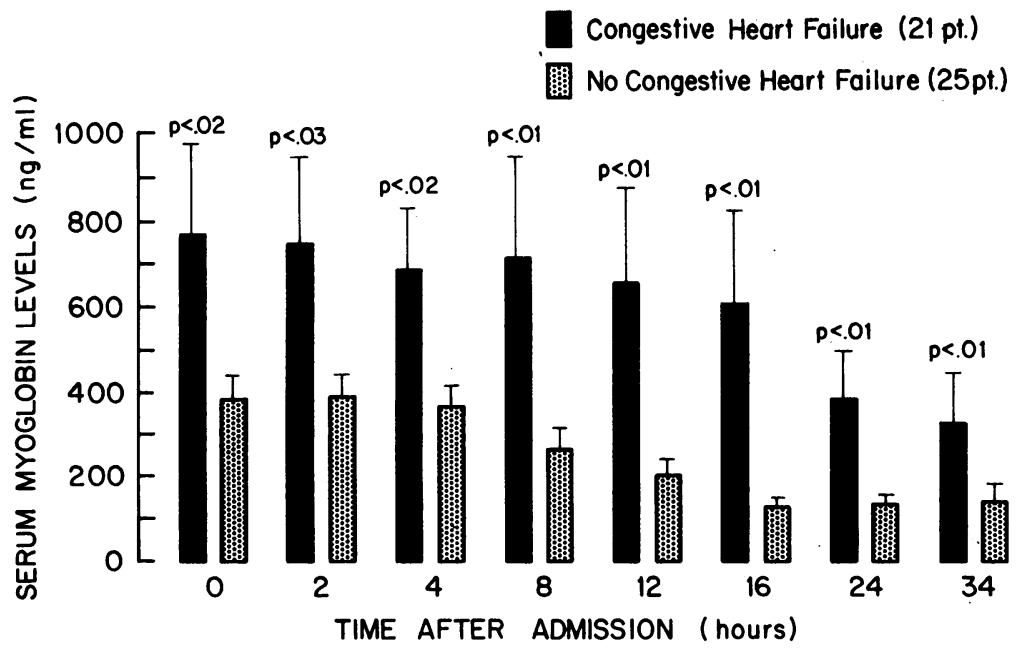

Fig. 3 Serial serum myoglobin levels in acute infarct patients with and without congestive heart failure. The values in patients with congestive heart failure were significantly higher than those in patients without failure at each interval tested. 
Most of these 44 patients were felt to have angina pectoris as the aetiology of their chest pain.

\section{CONGESTIVE HEART FAILURE WITHOUT} INFARCTION (Group V)

Seventeen of the non-infarct patients had clinical evidence of congestive heart failure on admission but only 1 of these (mentioned above) had a raised serum myoglobin level (Fig. 1).

\section{OPEN HEART SURGERY (Group VI)}

Nineteen patients were studied before operation and 24 hours after operation; 5 of these patients were also studied either 5 or 12 hours after operation. Each of these patients had been on cardiopulmonary bypass and the majority of the procedures involved coronary artery revascularisation. Three of these patients were judged to have perioperative myocardial infarcts on the basis of postoperative electrocardiographic changes and technetium-99m stannous pyrophosphate myocardial scintigraphy. The preoperative myoglobin levels were normal in each patient and increased substantially during the first 24 hours after operation (Fig. 4), even in those patients without evidence of perioperative infarction.

CARDIAC CATHETERISATION (Group VII)

Nine patients undergoing left heart catheterisation with left ventricular angiography and coronary arteriography had serum myoglobin determinations performed before the procedure and at 1,5 , and 24 hours after catheterisation. The control values were normal in each patient (mean \pm SE $37 \pm 5 \cdot 7$ $\mathrm{ng} / \mathrm{ml}$ ) and in none of the patients was there a rise outside the normal range ( $>85 \mathrm{ng} / \mathrm{ml}$ ) (Fig. 5).

EXERCISE STUDIES (Group VIII)

In 7 patients who underwent diagnostic bicycle exercise testing, serum myoglobin levels were obtained before and at serial intervals up to 24 hours after exercise. These patients were exercised because of chest pain suggesting coronary artery disease and they exercised to individually determined maximal levels (work load range 150-900 kilopondmetres/min, corresponding to oxygen uptakes of 0.6 to $2.11 / \mathrm{min}$ ). None developed serum myoglobin levels outside the normal range; the mean values for the entire group were $31 \pm 2.5 \mathrm{ng} / \mathrm{ml}$ before exercise and $34 \pm \mathbf{2 \cdot 4} \mathrm{ng} / \mathrm{ml}$ after exercise.

RHABDOMYOLYSIS (Group IX)

Five patients with evidence of skeletal muscle damage were studied. None of these individuals had clinical or laboratory evidence of myocardial infarction. Serum myoglobin levels were raised in all instances (range 245-1880 $\mathrm{ng} / \mathrm{ml}$ ).
OPEN HEART SURGERY

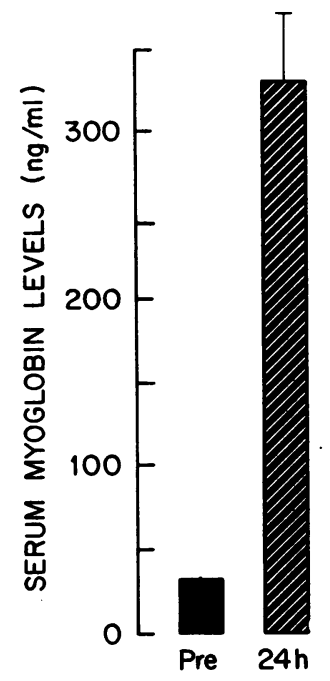

Fig. 4 Serum myoglobin levels in 19 patients undergoing cardiac surgery. The group mean level preoperatively was $33 \pm 3.0 \mathrm{ng} / \mathrm{ml}$ and $329 \pm 39 \mathrm{ng} / \mathrm{ml} 24$ hours postoperatively. Values in 5 of these patients studied at 5 or 12 hours postoperatively also were raised (range 166-470 $n g(m l)$

\section{Discussion}

The data obtained in the present studies confirm and extend our preliminary findings using myoglobin radioimmunoassay in patients with acute myocardial infarction (Stone et al., 1975). Patients with acute infarcts have serum myoglobin levels which are about ten times higher on average than those found in normal individuals. This profound rise in serum myoglobin concentration is maximal

\section{CARDIAC CATHETERIZATION}

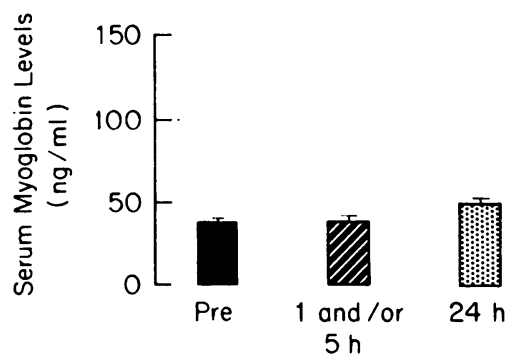

Fig. 5 Serum myoglobin levels in 9 patients undergoing cardiac catheterisation. Values remained normal in every patient during the 24-hour interval after the procedure. 
within 4 hours after admission to the hospital in most patients and usually falls toward normal subsequently. Though it is difficult accurately to date the onset of infarction in patients, two lines of evidence strongly suggest that release of myoglobin into the circulation is an early consequence of myocardial necrosis. First, in 45 per cent of patients, the rise in serum myoglobin level preceded any rise in total serum creatine kinase. Second, in studies to be reported elsewhere we have shown that serum myoglobin levels begin to rise within 2 hours and peak in 6 hours after experimentally-induced acute myocardial infarction in awake, unsedated closed chest dogs (Willerson et al., 1976).

It appears that necrosis of cardiac muscle is necessary for myoglobin release since serum levels remained normal in most patients admitted for chest pain who did not subsequently have evidence of acute myocardial infarction. It should be noted that many of these patients had chest pain of cardiac origin (angina pectoris and acute coronary insufficiency). Similarly, serum myoglobin levels were normal in 16 of 17 patients with congestive heart failure (without acute myocardial infarcts) and after moderately heavy exercise of short duration or cardiac catheterisation. Our previous studies indicated that intramuscular injections also did not raise serum myoglobin levels outside the normal range (Stone et al., 1975). The consistently raised serum myoglobin levels noted in patients after open heart surgery or in subjects with rhabdomyolysis is not surprising (Kagen, 1967, 1973). Myoglobins of skeletal and cardiac muscle origin are immunochemically indistinguishable and, therefore, our radioimmunoassay is not specific for the cardiac muscle protein. Thus, a raised serum myoglobin level must be interpreted with caution and in the appropriate clinical context. Despite this limitation, the test appears valuable in the initial evaluation of patients admitted to the hospital with chest pain and a provisional diagnosis of acute myocardial infarction. Additionally, the assay should prove useful in patients in whom skeletal muscle necrosis occurs. Studies are currently in progress in this laboratory to establish this point firmly.

Various methods have been advocated as ways of assessing the extent of myocardial infarction in patients and experimental animals (Shell et al., 1971; Maroko et al., 1971; Willerson et al., 1975b; Stokely et al., 1976). The serum myoglobin level may constitute another useful measure in this regard. In dogs with acute infarction produced by proximal left anterior descending coronory artery occlusion, peak serum myoglobin levels strongly correlate with infarct size determined histologically (Willerson et al., 1976). Moreover, this correlation is similar to that observed with other methods such as creatine kinase release, praecordial electrocardiographic mapping, and technetium-99m stannous pyrophosphate myocardial scintigraphy (Poliner et al., 1976). Thus, serum myoglobin determined by radioimmunoassay may be useful in estimating the relative extent of infarct size as well as in its diagnosis.

The authors thank Dr. C. Lynn Skelton for the opportunity to obtain serum samples from patients undergoing cardiac catheterisation, Dr. Richard Browne for statistical assistance, Dr. Robert Harris for technical assistance and Dr. Celso E. GomezSanchez for advice.

\section{References}

Holman, B. L., Lesch, M., Zweiman, F. G., Temte, J., Lown, B., and Gorlin, R. (1974). Detection and sizing of acute myocardial infarcts with $99 \mathrm{~m} \mathrm{Tc}(\mathrm{Sn})$ tetracycline. New England fournal of Medicine, 291, 159-163.

Jutzy, R. V., Nevatt, G. W., Palmer, F. J., and Nelson, J. C. (1975). Radioimmunoassay of serum myoglobin in acute myocardial infarction (abstract). American fournal of Cardiology, 35, 147.

Kagen, L., Scheidt, S., Roberts, L., Porter, A., and Paul, H. (1975). Myoglobinemia following acute myocardial infarction. American fournal of Medicine, 58, 177-182.

Kagen, L. J. (1967). Immunologic detection of myoglobinuria after cardiac surgery. Annals of Internal Medicine, 67, 1183-1189.

Kagen, L. J. (1973). Clinical considerations. In Myoglobin, p. 79. Columbia University Press, New York.

Kessler, H. A., Liebson, P. R., Mattenheimer, H., and Adams, E. C. (1975). Acute myocardial infarction diagnosed by myoglobinuria. Archives of Internal Medicine, 135, 11811183.

Maroko, P. R., Kjekshus, J., Sobel, B. E., Watanabe, T., Covell, J. W., Ross, J. J., and Braunwald, E. (1971). Factors influencing infarct size following experimental coronary artery occlusions. Circulation, 43, 67-82.

Poliner, L., Buja, L. M., Stokely, E. M., Parkey, R. W., Stone, M. J., Bonte, F. J., and Willerson, J. T. (1976). Infarct sizing in awake, unsedated dogs with acute anterior myocardial infarction (abstract). Clinical Research, 24, 235A.

Saranchak, H. J., and Bernstein, S. H. (1974). A new diagnostic test for acute myocardial infarction. The detection of myoglobinuria by radioimmunodiffusion assay. Fournal of the American Medical Association, 228, 1251-1255.

Siegel, S. (1956). Non Parametric Statistics for the Behavioral Sciences, p. 116. McGraw-Hill, New York.

Shell, W. E., Kjekshus, J., and Sobel, B. E. (1971). Quantitative assessment of the extent of myocardial infarction in the conscious dog by means of analysis of serial changes in serum creatine phosphokinase activity. Fournal of Clinical Investigation, 50, 2614-2625.

Stokely, E. M., Buja, L. M., Lewis, S. E., Parkey, R. W., Bonte, F. J., Harris, R. A., Jr., and Willerson, J. T. (1976). Measurement of acute myocardial infarcts in dogs with ${ }^{99} \mathrm{mTc}$ stannous pyrophosphate scintigrams. Fournal of Nuclear Medicine, 17, 1-5.

Stone, M. J., Willerson, J. T., Gomez-Sanchez, C. E., and Waterman, M. (1975). Radioimmunoassay of myoglobin in human serum. Results in patients with acute myocardial infarction. Fournal of Clinical Investigation, 56, 1334-1339. 
Wagner, G. S., Roe, C. R., Limbird, L. E., Rosati, R. A., and Wallace, A. G. (1973). The importance of identification of the myocardial-specific isoenzyme of creatine phosphokinase (MB form) in the diagnosis of acute myocardial infarction. Circulation, 47, 263-269.

Willerson, J. T., Parkey, R. W., Bonte, F. J., Meyer, S. L., Atkins, J. M., and Stokely, E. M. (1975a). Technetium stannous pyrophosphate myocardial scintigrams in patients with chest pain of varying etiology. Circulation, 51, 10461052.

Willerson, J. T., Parkey, R. W., Buja, L. M., Harris, R. A., Jr., Stokely, E. M., Blomqvist, G., and Bonte, F. J. (1975b). Sizing acute myocardial infarction utilizing technetium stannous pyrophosphate myocardial scintigrams in dogs and man (abstract). Circulation, 52, 11-108.

Willerson, J. T., Poliner, L., Buja, L. M., Waterman, M., Gomez-Sanchez, C. E., Templeton, G. H., and Stone, M. J. (1976). Myoglobinemia as a clue to the presence of acute myocardial infarction (abstract). Clinical Research, 24, 422A.

Requests for reprints to Professor James $T$. Willerson, Ischemic Heart Center, L5-134, The University of Texas Health Science Center at Dallas, 5323 Harry Hines Boulevard, Dallas, Texas 75235, U.S.A. 